\title{
Operational test of bonded magnetocaloric plates
}

Bahl, Christian; Navickaité, Kristina; Neves Bez, Henrique; Lei, Tian; Engelbrecht, Kurt; Bjørk, Rasmus; Li, Ke ; Li, Zhenxing ; Shen, Jun; Dai, Wei

Total number of authors:

15

Published in:

International Journal of Refrigeration

Link to article, DOI:

10.1016/j.ijrefrig.2017.02.016

Publication date:

2017

Document Version

Peer reviewed version

Link back to DTU Orbit

Citation (APA):

Bahl, C., Navickaité, K., Neves Bez, H., Lei, T., Engelbrecht, K., Bjørk, R., Li, K., Li, Z., Shen, J., Dai, W., Jia, J., Wu, Y., Long, Y., Hu, F., \& Shen, B. (2017). Operational test of bonded magnetocaloric plates. International Journal of Refrigeration, 76, 245-251. https://doi.org/10.1016/j.ijrefrig.2017.02.016

\section{General rights}

Copyright and moral rights for the publications made accessible in the public portal are retained by the authors and/or other copyright owners and it is a condition of accessing publications that users recognise and abide by the legal requirements associated with these rights.

- Users may download and print one copy of any publication from the public portal for the purpose of private study or research.

- You may not further distribute the material or use it for any profit-making activity or commercial gain

- You may freely distribute the URL identifying the publication in the public portal 


\title{
Operational test of bonded magnetocaloric plates
}

Christian R.H. Bahl, Kristina Navickaitè, Henrique Neves Bez, Tian Lei, Kurt Engelbrecht, Rasmus Bjørk

Department of Energy Conversion and Storage, Technical University of Denmark, Frederiksborgvej 399, DK-4000 Roskilde, Denmark

Ke Li, Zhenxing Li, Jun Shen, Wei Dai

Technical Institute of Physics and Chemistry, Chinese Academy of Sciences, Beijing 100190, China

Jichen Jia, Yuanyuan Wu, Yi Long

University of Science and Technology Beijing, Beijing 100083, China

Fengxia $\mathrm{Hu}$, Baogen Shen

Institute of Physics, Chinese Academy of Sciences, Beijing 100190, China

\begin{abstract}
Bonded plates made by hot pressing $\mathrm{La}_{0.85} \mathrm{Ce}_{0.15} \mathrm{Fe}_{11.25} \mathrm{Mn}_{0.25} \mathrm{Si}_{1.5} \mathrm{H}_{y}$ particles and resin have been tested as active magnetic regenerators in a small scale magnetocaloric device. Firstly the plates were carefully characterised magnetically and thermally. The plates were prepared with 5 wt\% resin, and from density measurements it was found that the volume ratio of the magnetocaloric material in the plates was 0.53 , due to the resin and porosity. The best operating conditions for the plate regenerator were determined at which a temperature span of $6.4 \mathrm{~K}$ was measured along the plates.
\end{abstract}

Keywords: Magnetocaloric, Magnetic refrigerator, Regenerator, Resin bonding 


\section{Nomenclature}

\begin{tabular}{|ll|}
\hline Abbreviations & \\
AMR & Active magnetic regenerator \\
DSC & Differential scanning calorimeter \\
EDS & Energy-dispersive X-ray spectroscopy \\
Gd & Gadolinium \\
PPMS & Physical properties measurement system \\
SEM & Scanning electron microscope \\
TTO & Thermal transport option \\
VSM & Vibration sample magnetometer \\
\hline
\end{tabular}

\begin{tabular}{|ll|}
\hline Variables & \\
$c$ & Specific heat \\
$c_{\mathrm{H}}$ & Specific heat at constant magnetic field \\
$m$ & Mass \\
$T_{\mathrm{hot}}$ & Hot end temperature \\
$\Delta S_{\mathrm{M}}$ & Magnetic isothermal entropy change \\
$\Delta T_{\mathrm{ad}}$ & Adiabatic temperature change \\
$\Delta T_{\text {effective }}$ & Effective adiabatic temperature change \\
$\Delta T_{\mathrm{span}}$ & Temperature span \\
$\phi$ & Utilisation \\
\hline
\end{tabular}

\begin{tabular}{|ll|}
\hline Subscripts & \\
$\mathrm{f}$ & Fluid \\
$\mathrm{MCM}$ & Magnetocaloric material \\
resin & Resin binder material \\
$\mathrm{s}$ & Solid \\
\hline
\end{tabular}




\section{Introduction}

For the past decade significant progress has been made in bringing magnetic refrigeration towards commercialisation. New magnetocaloric materials have been developed and magnetocaloric demonstration devices become ever more powerful and efficient (Kitanovski et al., 2015). Most of these devices have employed the so called active magnetic regenerator (AMR) cycle as a method of utilising the magnetocaloric effect in a device. Here the temperature of a porous regenerator structure is increased and decreased by applying and removing a magnetic field, while a heat transfer fluid is reciprocated back and forth in order to build up a temperature gradient. Keys to utilising the AMR concept are firstly to have a magnetocaloric material, or a cascade of such, with high magnetocaloric effect, and secondly, to shape this material in a way that there is good thermal contact between solid and fluid, allowing an effective heat transfer as, e.g., discussed in (Ferreira et al., 2014).

Many magnetocaloric materials have been studied and considered for application in devices (Smith et al., 2012). Recently a lot of research has been done on materials that undergo a first order magnetic phase transition, so-called first order materials, as they have a very high magnetic entropy change $\Delta S_{\mathrm{M}}$ around the phase transition. An important example of this class of materials is the intermetallic $\mathrm{La}(\mathrm{Fe}, \mathrm{Si}){ }_{13} \mathrm{H}_{y}$, which has been studied with a number of different elements doped into the Fe and Si sites (Zhang et al., 2013). In general this material series has a high magnetocaloric effect, a tunable Curie temperature and only a small amount of undesirable thermal hysteresis. The disadvantage of these materials is the lack of structural stability due to the volume change at the phase transition (Lyubina et al., 2010).

Recently, different strategies for shaping these and similar magnetocaloric materials into the desired shapes have been proposed and tested. Polymer bonding and pressing to plates has been demonstrated for first order materials (Skokov et al., 2014; Radulov et al., 2015) and second order materials of the same type (Pulko et al., 2015). Other methods of producing structures have also been presented, such as injection moulding (Lanzarini et al., 2015), hot pressing with $\mathrm{Cu}$ (Liu et al., 2015) and extrusion into monoliths (Pryds et al., 2011). Actual AMR performance in a test device has only been reported for the second order bonded plates (Pulko et al., 2015). However, porous particle based regenerators where the particles are bonded for stability have been presented, most notably by Jacobs et al. (2014) using 
$\mathrm{La}(\mathrm{Fe}, \mathrm{Si})_{13} \mathrm{H}_{y}$.

Here we demonstrate in a small versatile AMR device the performance of plates of first order materials bonded with resin and cured during pressing.

\section{Experimental}

A $\mathrm{La}_{0.85} \mathrm{Ce}_{0.15} \mathrm{Fe}_{11.25} \mathrm{Mn}_{0.25} \mathrm{Si}_{1.5}$ ingot was prepared in an induction furnace. The purity of the raw materials was at least $99.9 \mathrm{wt} \%$. The annealed ingots were crushed into particles less than $0.35 \mathrm{~mm}$ in size for the hydrogenation process. These were annealed in a high purity hydrogen atmosphere until saturation. The structure of the hydrides was confirmed by x-ray powder diffraction. The hydrogen concentration $y$ of $\mathrm{La}_{0.85} \mathrm{Ce}_{0.15} \mathrm{Fe}_{11.25} \mathrm{Mn}_{0.25} \mathrm{Si}_{1.5} \mathrm{H}_{y}$ (referred to as LaFeSiH in the following) was estimated to be $0.2 \mathrm{wt} \%$ by the inert gas pulse infrared absorption method. When vacuum annealing under $350{ }^{\circ} \mathrm{C}$ for 2 hours a sharp decrease of the Curie temperature was observed due to the escape of $\mathrm{H}$.

\subsection{Processing the plates}

The resulting powder was mixed with a phenolic resin system in a mass ratio of 20:1. The mixed powders were pressed into plate shape under pressure of $20 \mathrm{MPa}$ and then solidified at $150{ }^{\circ} \mathrm{C}$ for 10 minutes, as shown in Figure 1. The plates were prepared in the size $25 \mathrm{~mm}$ by $40 \mathrm{~mm}$, in order to fit into the regenerator test device, with a thickness of $0.5 \mathrm{~mm}$. Measuring the specific heat shows that the Curie temperature does not change during the resin curing process, indicating that the LaFeSiH is unaffected by this treatment.

\subsection{Characterisation of the plates}

Thermal conductivity was measured at $300 \mathrm{~K}$ using a Thermal Transport Option (TTO) on a Quantum Design physical property measurement system (PPMS). The density of the plates was measured using AccuPyc 1340 helium pycnometer repeating each measurement 10 times, and the density of the resin was measured with a Pentapyc5200e Auto Density Analyzer. The magnetic properties were analysed in a LakeShore 7407 vibrating sample magnetometer (VSM). The sample was measured in the temperature range $270 \mathrm{~K}-306 \mathrm{~K}$ at applied fields up to $1.5 \mathrm{~T}$. The specific heat of the sample was measured using a custom built differential scanning calorimeter (DSC), allowing the applied field to be varied in the range 0-1.6 $\mathrm{T}$ at a fixed 


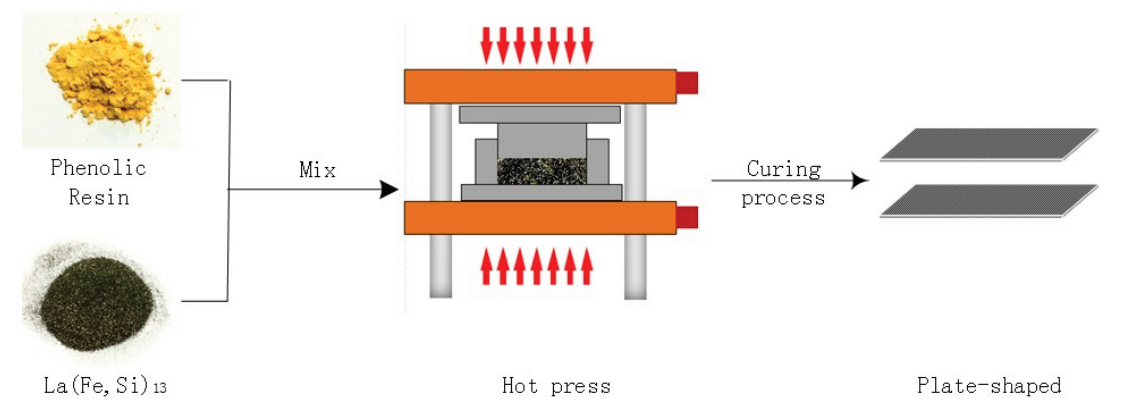

Fig. 1: Illustration of the fabrication process, showing the mixing of powder with resin, hot pressing and the final plates.

orientation relative to the sample (Jeppesen et al., 2008). A scanning electron microscope (SEM), Hitachi TM3000, equipped with a Bruker Quantax Energy-dispersive X-ray spectroscopy detector (EDS) was used to analyse the microstructure of a piece of one of the plates.

\section{Results}

\subsection{Physical properties of the plates}

Figure 2 shows the structure of a plate. It consists of irregular particles of LaFeSiH with a broad size range. There is a significant porosity between the particles. Using EDS mapping we can probe the presence of the resin by isolating the carbon signal, as this will be unique to the resin. As shown in Figure 3 the resin covers large areas binding together the particles, but there are still significant volumes of porosity between particles. So the system can be considered to consist of three distinct volumes, LaFeSiH, resin and pores.

An average density value of 5721 was measured based on pieces of plates weighing in total $2.3947 \mathrm{~g}$. The mass fraction of magnetocaloric material is 0.95 and the mass fraction of resin is 0.05 . Based on the structural symmetry and lattice parameters the density of the $\mathrm{LaFeSiH}, \rho_{\mathrm{LaFeSiH}}$, is $7207 \mathrm{kgm}^{-3}$ and the density of the resin, $\rho_{\text {resin }}$, is $1166 \mathrm{kgm}^{-3}$ found by crushing down a sample of pure resin into a powder and measuring the density. Assuming that there are no pores closed to helium penetration, the weighted average density of the LaFeSiH and the resin is $5724 \mathrm{kgm}^{-3}$, very close to the measured value.

Geometrically measuring and weighing a plate gave a density of approximately $4000 \mathrm{kgm}^{-3}$, which includes all pores. From this we can calculate the 


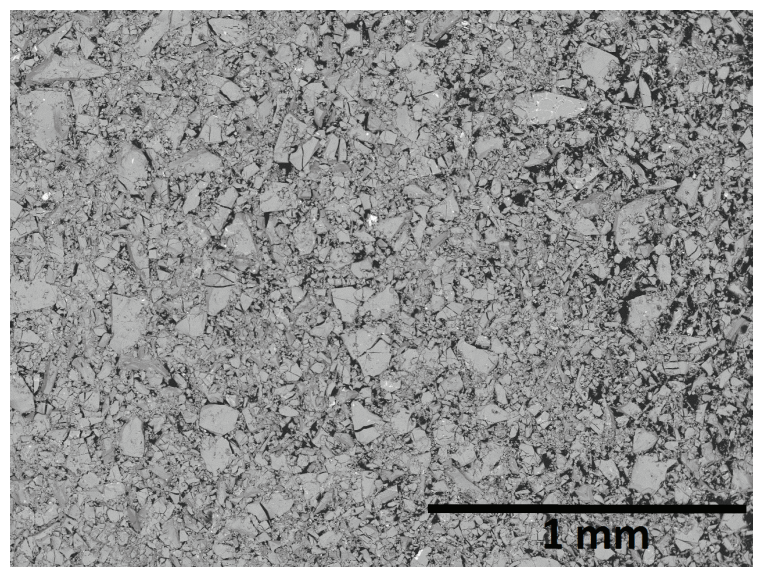

Fig. 2: Backscattered SEM image of an area of a plate. The image shows the surface of the plate as prepared.

porosity of the plates as 0.30. Thus the volume fractions of $\mathrm{LaFeSiH}$, resin and pores are approximately $0.53,0.17$ and 0.30 , respectively.

Based on the mass fractions of $\mathrm{LaFeSiH}$ and resin the reduction in effective adiabatic temperature change due to the presence of resin is quite limited. The actual temperature change $\Delta T_{\text {effective }}$ will be given by:

$$
\Delta T_{\text {effective }}=\frac{\Delta T_{\mathrm{ad}} c_{\mathrm{H}, \mathrm{MCM}}}{0.95 c_{\mathrm{H}, \mathrm{MCM}}+0.05 c_{\mathrm{H}, \mathrm{resin}}} \approx 0.94 \Delta T_{\mathrm{ad}},
$$

where $c_{\mathrm{H}, \mathrm{MCM}}$ and $\mathrm{c}_{\mathrm{H} \text {,resin }}$ are the specific heats of $\mathrm{LaFeSiH}\left(500 \mathrm{Jkg}^{-1} \mathrm{~K}^{-1}\right)$ and resin (1200 $\mathrm{Jkg}^{-1} \mathrm{~K}^{-1}$ ), respectively. As the peak of specific heat in $\mathrm{LaFeSiH}$ is very narrow and field dependent we use the background value away from the peak. Closer to the peak $\Delta T_{\text {effective }}$ will be even closer to $\Delta T_{\mathrm{ad}}$.

Magnetisation measurements were used to calculate the magnetic entropy change, $\Delta S_{\mathrm{M}}$, in the conventional way described by Pecharsky and Gschneidner Jr. (1999b). A piece of one of the plates was used with a mass of $11.76 \mathrm{mg}$ and approximate dimensions $2.8 \mathrm{~mm} \times 1.75 \mathrm{~mm} \times 0.6 \mathrm{~mm}$, keeping the field along the longest direction. This piece seemed free of resin, but there may be a little resin included. As the data is mass normalised any small amount of resin would only slightly change the level reached by the peak, but not the profile shape. The data was corrected for demagnetisation approximating the slightly irregular sample to a prism and using the expression by Aharoni (1998). 


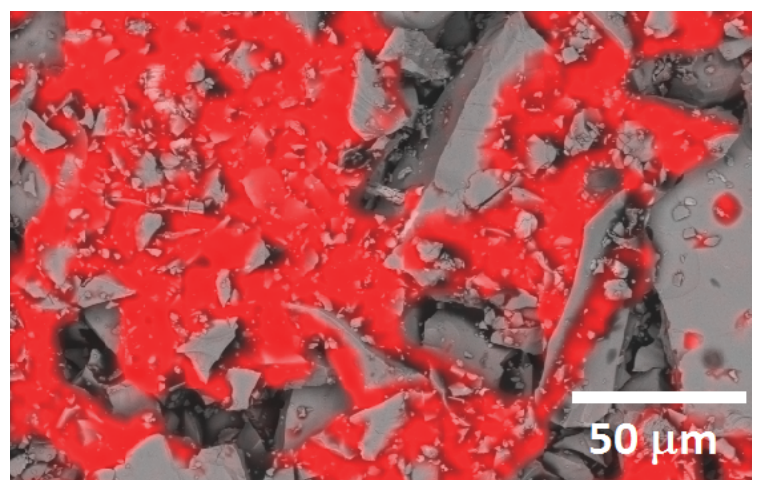

Fig. 3: EDS filtered to show carbon. The resin is observed to bind together the particles, but there is also a significant porosity (the darker areas) remaining as discussed in the text.

To probe for the presence of hysteresis the magnetic entropy was measured both during cooling and during heating. Between each measurement the sample was 'reset' at an equilibrium temperature far above or below the measurement range, for cooling and heating, respectively (Caron et al., 2009). The $\Delta S_{\mathrm{M}}$ values are consistent with those found in literature (Zhang et al., 2013). Figure 4 shows that the hysteresis at the phase transition is very low. In order to further probe the presence of hysteresis the specific heat of the sample was measured during heating and cooling at different temperature ramp rates in the range $1 \mathrm{Kmin}^{-1}$ to $5 \mathrm{Kmin}^{-1}$. By applying a linear regression of the peak temperatures with respect to the temperature rates, the hysteresis is found to be $0.4 \pm 0.2 \mathrm{~K}$, consistent with the magnetisation data, as shown in Figure 5.

When applying a magnetic field the temperature of the peaks of the specific heat increase at a rate of about $4.3 \mathrm{~K} \mathrm{~T}^{-1}$. Also, the peak goes from being very sharp to becoming more broad, as shown in Figure 6, which was measured at a rate of $1 \mathrm{~K} \mathrm{~min}^{-1}$. This is consistent with the results reported by Basso et al. (2015). Due to the very low value of the hysteresis and the errors on the lines fitted to the peak temperatures, determining the critical field at which the hysteresis vanishes cannot be done with confidence.

\subsection{Regenerator testing}

A stack of 25 plates was tested as an AMR in a small scale test device at the Technical University of Denmark. The stack was prepared as described in Engelbrecht et al. (2011) by layering the plates with $\varnothing 0.25 \mathrm{~mm}$ metal wire 


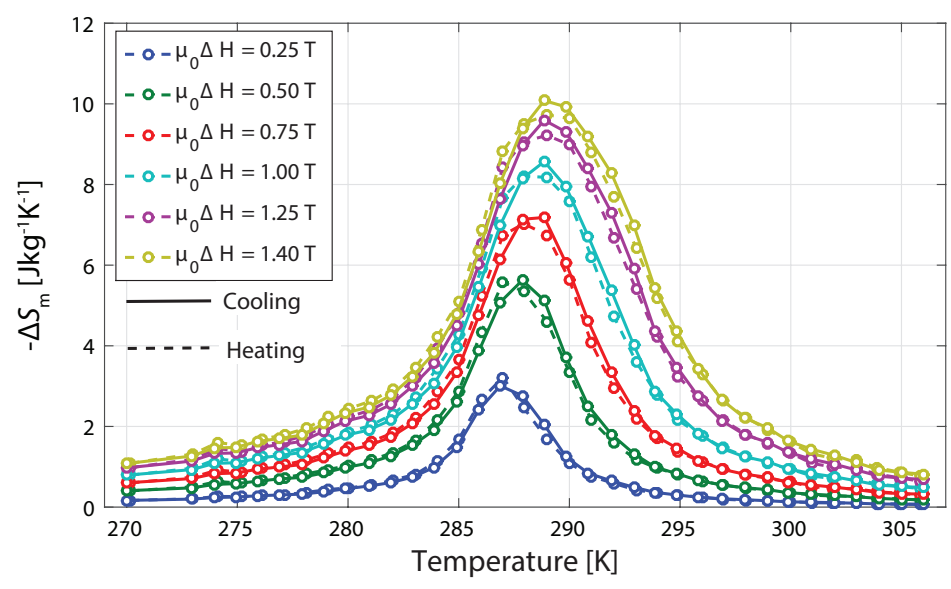

Fig. 4: Measured entropy change of a sample of one of the plates. Both the heating and cooling curves are shown, and the hysteresis is observed to be small. The legend indicates the internal field values.

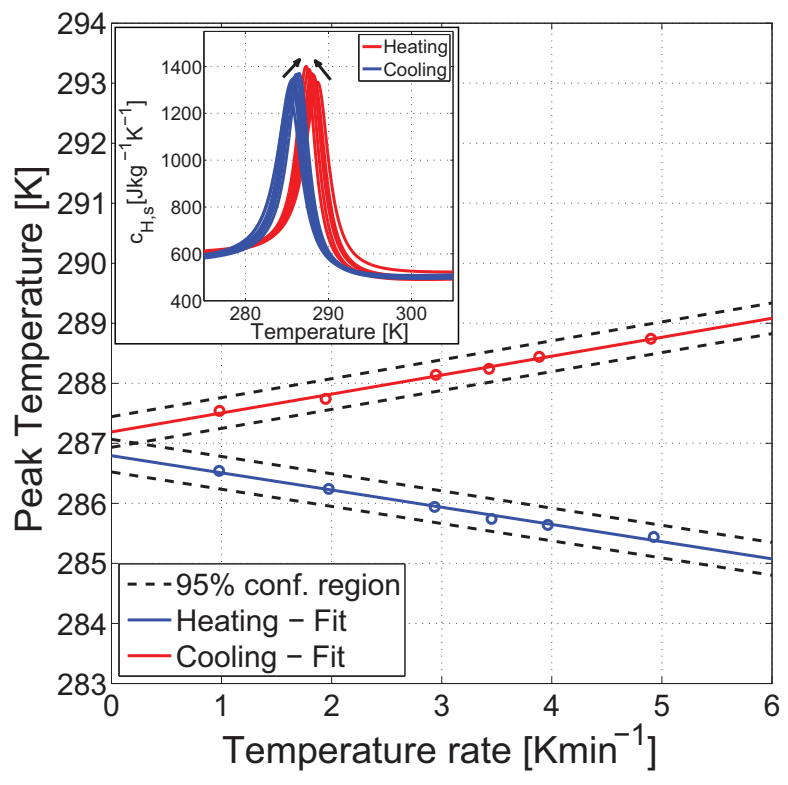

Fig. 5: The peak temperature of the specific heat measured at different ramp rates in the DSC. Both the heating peak and the cooling peak have been measured, as shown in the inset. Extrapolating to zero ramp rate gives a measure of the hysteresis. 


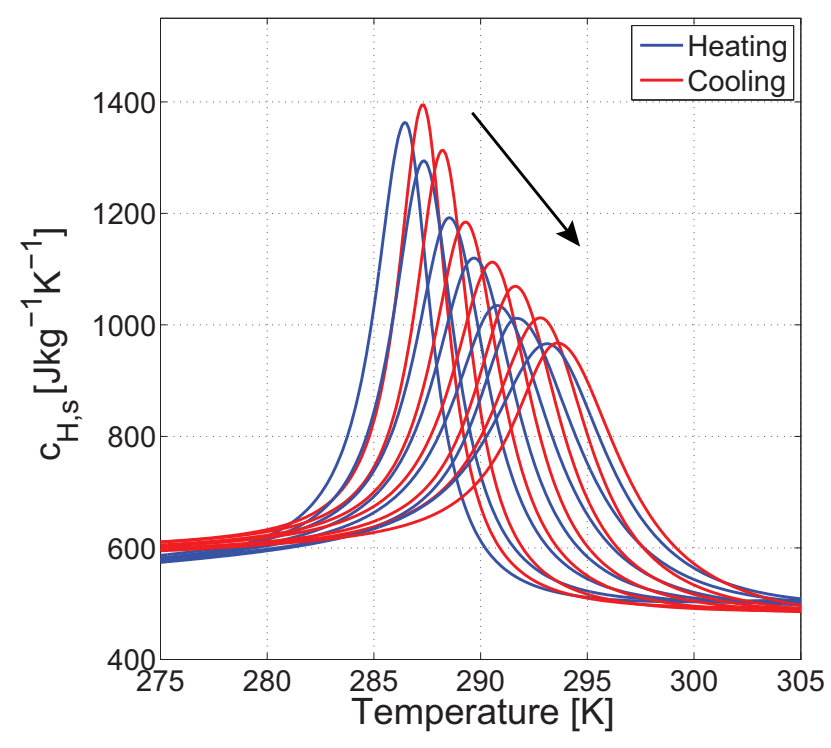

Fig. 6: Field dependence of the peak in specific heat, for cooling and heating. Applied fields of $0,0.25,0.50,0.75,1.00,1.25$ and $1.50 \mathrm{~T}$ are shown, with the peak moving up in temperature and broadening as the field increases. The arrow indicates the direction of increasing field.

as spacers. The sides were then sealed with epoxy before removing the metal wire. This resulted in a $20.5 \mathrm{~mm}$ tall stack, $25 \mathrm{~mm}$ wide and $40 \mathrm{~mm}$ long, which was then mounted in a cylindrical regenerator housing using silicone around the border of the stack. The mass of each plate was approximately 2 $\mathrm{g}$, so the mass of the regenerator was $50 \mathrm{~g}$.

The glued stack, before being mounted in the regenerator housing, is shown in Figure 7. The channels between the plates are clearly seen, but close inspection reveals that with the chosen plate spacing the unevenness of the plates becomes significant. Thus the actual channel height varies significantly across the regenerator. The effect of this will be discussed later.

Testing of the regenerator was done in the versatile test device described previously (Bahl et al., 2008; Engelbrecht et al., 2011). Here the cylindrical regenerator housing moves in and out of the bore of a $1.1 \mathrm{~T}$ permanent magnet Halbach cylinder. A $\varnothing 18 \mathrm{~mm}$ reciprocating piston forces the heat transfer fluid through the regenerator to perform the well known four steps of the AMR cycle (Pecharsky and Gschneidner Jr., 1999a). Demineralised water, mixed with 2 vol\% of ENTEK FNE corrosion inhibitor, as recommended for a similar material by Velazquez et al. (2014), was used as the 


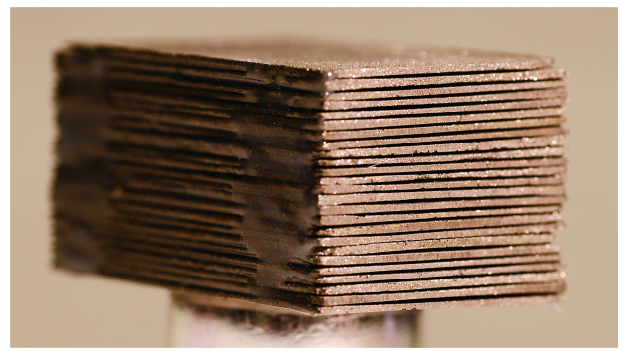

Fig. 7: The stack of plates used in the regenerator before being mounted in the cylindrical regenerator housing.

heat transfer fluid.

Three parameters were varied in the testing of the regenerator, the fluid velocity, the length the piston is moved, and the ambient temperature. A heat exchanger at the hot end of the regenerator keeps the temperature of this close to that of the temperature controlled cabinet, in which the device is mounted. The length the piston moves is conventionally expressed as the utilisation, $\phi$, defined as(Bahl et al., 2012)

$$
\phi=\frac{m_{\mathrm{f}} c_{\mathrm{f}}}{m_{\mathrm{s}} c_{\mathrm{H}, \mathrm{s}}}
$$

where $m_{\mathrm{f}}$ is the mass of the fluid pushed through the regenerator in one blow, $c_{\mathrm{f}}$ is the specific heat of the fluid, $m_{\mathrm{s}}$ is the mass of the solid regenerator and $c_{\mathrm{H}, \mathrm{s}}$ is the specific heat of the bonded plates. $m_{\mathrm{f}}$ is found from the movement of the $\varnothing 18 \mathrm{~mm}$ piston, $c_{\mathrm{f}}$ is set as the textbook value of $4200 \mathrm{Jkg}^{-1} \mathrm{~K}^{-1}$, ignoring the small amount of corrosion inhibitor, $m_{\mathrm{s}}$ is $50 \mathrm{~g}$ and for $c_{\mathrm{H}, \mathrm{s}}$ the background value of $600 \mathrm{Jkg}^{-1} \mathrm{~K}^{-1}$ is used, as found from Figure 6, including the resin.

Starting at an ambient temperature of $290 \mathrm{~K}$ and a utilisation of 0.23 , the AMR cycle is repeated until the temperature difference between the cold end and the hot end, known as the temperature span, $\Delta T_{\text {span }}$, reached a constant value. Different values of the fluid velocity were tested recording the achieved $\Delta T_{\text {span }}$, as shown in Figure 8. Note that the fluid velocity reported is the average velocity in the channels based on the movement of the piston and cross-sections of the channels and tube. It is observed that the highest values of the span are found in a broad optimum around about $7 \mathrm{mms}^{-1}$, which is consistent with that previously found for plates of a similar material (Engelbrecht et al., 2011). The plates in Engelbrecht et al. (2011) 
were somewhat thicker and cut from blocks made of different $\mathrm{La}(\mathrm{Fe}, \mathrm{Co}, \mathrm{Si})_{13}$ compounds, all with a second order phase transition. Using this fluid velocity of $7 \mathrm{mms}^{-1}$ and staying at an ambient temperature of $290 \mathrm{~K}$ the utilisation was varied to find the best performance, as shown in Figure 9. Again a broad peak of $\Delta T_{\text {span }}$ is observed, the utilisation giving the highest values being about 0.23, similar to Engelbrecht et al. (2011); Bahl et al. (2012). Due to the change in the distance and velocity of the piston movement the cycle time varies in the range of 5 to $24 \mathrm{~s}$ in Figure 8 and in the range 5.5 $12 \mathrm{~s}$ in Figure 9.

The magnetocaloric effect in materials with a first order magnetic phase transition occurs over a narrow range of temperatures, as shown in Figure 4. Thus it is very important when utilising these materials in a device that the span of the device is across the peak in magnetocaloric effect. Figure 10 shows the achieved span of the device as the hot end temperature is changed, while keeping a utilisation of 0.23 and a fluid velocity of $7 \mathrm{mms}^{-1}$. The cycle time remains constant at about $9 \mathrm{~s}$. We observe a relatively narrow peak that drops off sharply at $293 \mathrm{~K}$, which is a few degrees above the peak temperature of $\Delta S_{\mathrm{M}}$ in a $1 \mathrm{~T}$ field. The maximum $\Delta T_{\text {span }}$ was $6.4 \mathrm{~K}$, which is around double the maximum adiabatic temperature change of such a material in this applied field, see e.g. Basso et al. (2015), demonstrating the AMR cycle in the regenerator. The maximum span is lower than the 10.2 K span achieved using plates of the benchmark material Gd (Engelbrecht et al., 2011), but comparable to the spans achieved using plates of a single second order LaFeCoSi material or the single perovskite type material $\mathrm{La}_{0.67} \mathrm{Ca}_{0.26} \mathrm{Sr}_{0.07} \mathrm{Mn}_{1.05} \mathrm{O}_{3}$ (Pulko et al., 2015; Engelbrecht et al., 2011). When grading the regenerator to two similar materials with Curie temperatures close to each other the span can be significantly increased for both the LaFeCoSi type materials (Engelbrecht et al., 2011) and the perovskite type materials (Bahl et al., 2012). Layering materials is key to the success of first order materials, due to the narrow peaks of the magnetocaloric effect, so it is clearly expected that if a regenerator were constructed with a number of different Curie temperatures along the flow direction significantly higher performance could be reached. However, as shown recently it is extremely important to have the correct spacing of the Curie temperatures, as the performance can easily be significantly reduced if this is not the case (Lei et al., 2015). 


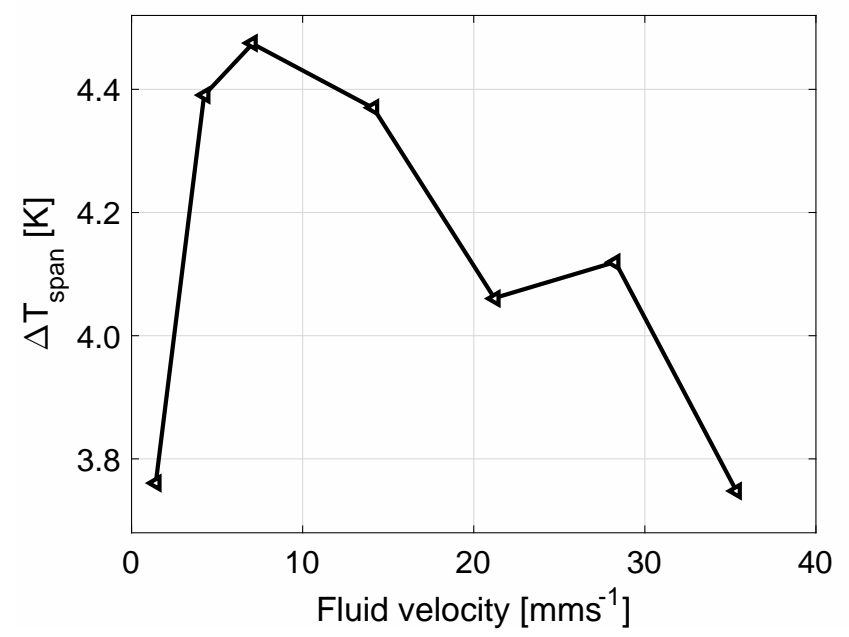

Fig. 8: The steady state temperature span between the hot and the cold end as a function of the velocity of the fluid being pushed between the plates. The data is obtained at an ambient temperature of $290 \mathrm{~K}$ and a utilisation of 0.23 .

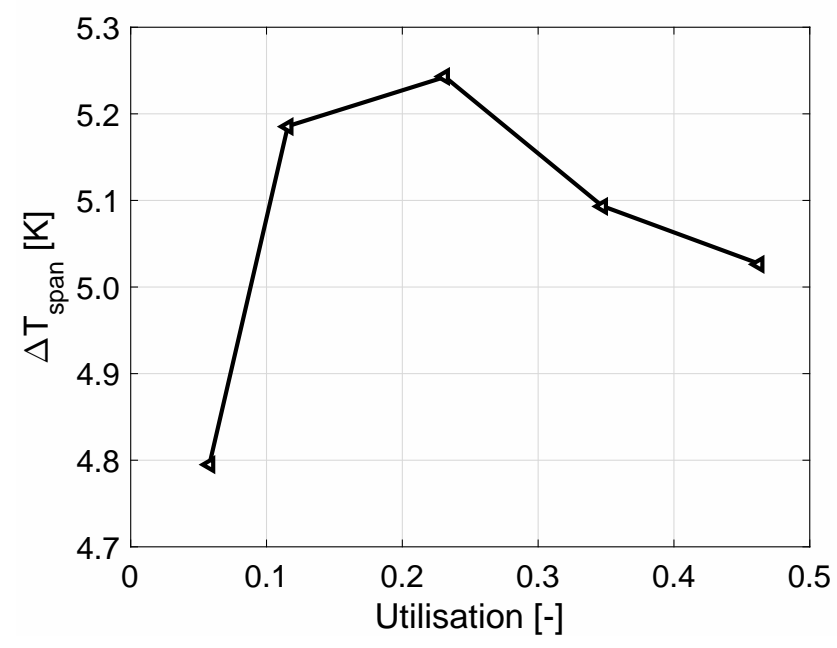

Fig. 9: The steady state temperature span between the hot and the cold end as a function of the utilisation. The data is obtained at an ambient temperature of $290 \mathrm{~K}$ and a fluid velocity of $7 \mathrm{mms}^{-1}$. 


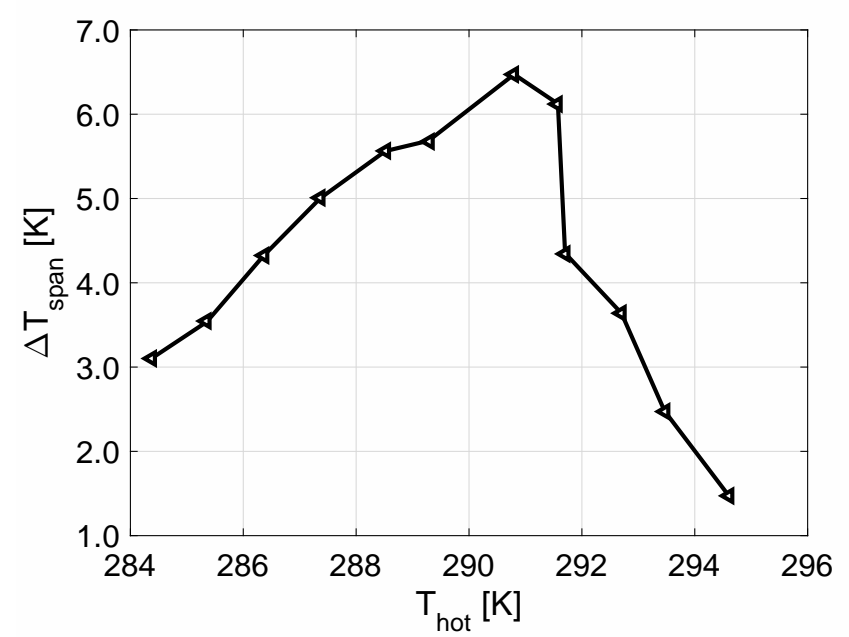

Fig. 10: The steady state temperature span between the hot and the cold end as a function of the constant hot end temperature. The data is obtained at a utilisation of 0.23 and a fluid velocity of $7 \mathrm{mms}^{-1}$.

\section{Discussion}

The measured maximum temperature span of $6.4 \mathrm{~K}$ is relatively low compared to other reported spans from this and similar devices. But when using just a single first order material, there is a natural limit to the achievable span, due to the very narrow $\Delta S_{\mathrm{M}}$ peak. This span may be expanded by layering materials with slightly different Curie temperatures, as done by Jacobs et al. (2014). Previously it has been shown how thin plates consisting of a number of magnetocaloric materials have been produced by tape casting (Bulatova et al., 2015). A similar production technique could be imagined for hot-pressing single plates consisting of multiple materials.

Regenerator performance is heavily influenced by the morphology of the regenerator. In the present study flat parallel plates were chosen, giving a regenerator with a significantly reduced pressure drop compared to an equivalent packed bed one. Lower pressure drop leads to higher efficiency, although this is not measured in the device used here. The disadvantage of plates is the demand for thin very parallel plates with small plate spacing, which is often hard to realise. The increase of the Biot number for thicker plates will result in a slower heat transfer to the surrounding fluid, preventing fast operation and high performance. A higher thermal conductivity will allow for the use of thicker plates. The thermal conductivity of the plates tested here has 
been measured to be $3.13 \mathrm{Wm}^{-1} \mathrm{~K}^{-1}$, reduced from the generally accepted value of about $9 \mathrm{Wm}^{-1} \mathrm{~K}^{-1}$ for this type of material (Fujieda et al., 2004), due to porosity and the presence of resin in the plates. In order to realise the full potential of plates with this relatively low thermal conductivity the thickness would have to be significantly reduced, and the channel thicknesses be reduced accordingly.

In addition to the challenges of producing significantly thinner plates the flatness requirement of such plates will also become more critical. The reduction in regenerator performance due to a maldistribution of the plate spacings has been shown both by modelling and experimentally (Nielsen et al., 2012; Engelbrecht et al., 2013). Even seemingly insignificant variation in the channel thicknesses can have a large impact. With sub-millimeter plates a requirement of less than $10 \%$ variation in spacing, in accordance with the general recommendation in Nielsen et al. (2012), will necessitate very accurate production techniques.

Although the addition of the low mass fraction resin hardly influences $\Delta S_{\mathrm{M}}$ per unit mass, the volumetric $\Delta S_{\mathrm{M}}$ decreases from about $70 \mathrm{mJcm}^{-3} \mathrm{~K}^{-1}$ to about $40 \mathrm{mJcm}^{-3} \mathrm{~K}^{-1}$ due to the porous structure of the bonded material under a changing magnetic field of 1.4 T. From a practical point of view, the volumetric $\Delta S_{\mathrm{M}}$ is of more importance (Gschneidner Jr. et al., 2005), since the magnetic system is the most expensive part and the magnetic field volume is thus limited. This is a challenge when making bonded plates and reducing the amount of resin to the minimum amount that will still maintain the structural integrity of the plates should be considered. Also, the 0.30 volume fraction of pores could possibly be reduced by improving the processing route.

\section{Conclusion}

We have shown that it is possible to use resin bonded plates of the magnetocaloric material $\mathrm{La}_{0.85} \mathrm{Ce}_{0.15} \mathrm{Fe}_{11.25} \mathrm{Mn}_{0.25} \mathrm{Si}_{1.5} \mathrm{H}_{y}$ as regenerators in a small scale magnetocaloric testing device. The plates were characterised thermally and magnetically to determine the magnetic entropy change, the heat capacity and the hysteresis. The maximum achieved temperature span was $6.4 \mathrm{~K}$. Increasing this span may be achieved by layering materials, reducing the amount of resin and pores or by manufacturing thinner and flatter plates. 


\section{Acknowledgements}

The authors acknowledge the International Network Programme: Rareearth/transition-metal oxides and compounds for environment friendly energy science and technology (grant no 4070-00047) from The Danish Agency for Science, Technology and Innovation. This work is supported by National Natural Science Foundation of China (51322605, 51571018, 51531008) and also partly financed by the ENOVHEAT project which is funded by Innovation Fund Denmark (contract no 12-132673). 
Aharoni, A., 1998. Demagnetizing factors for rectangular ferromagnetic prisms. J. Appl. Phys. 83, 3432.

Bahl, C. R. H., Petersen, T. F., Pryds, N., Smith, A., 2008. A versatile magnetic refrigeration test device. Rev. Sci. Instrum. 79, 093906.

Bahl, C. R. H., Velazquez, D., Nielsen, K., Engelbrecht, K., Andersen, K., Bulatova, R., Pryds, N., 2012. High performance magnetocaloric perovskites for magnetic refrigeration. Appl. Phys. Lett. 100, 121905.

Basso, V., Küpferling, M., Curcio, C., Bennati, C., Barzca, A., Katter, M., Bratko, M., Lovell, E., Turcaud, J., Cohen, L., 2015. Specific heat and entropy change at the first order phase transition of $\mathrm{La}(\mathrm{Fe}-\mathrm{Mn}-\mathrm{Si})_{13}-\mathrm{H}$ compounds. J. Appl. Phys 118, 053907.

Bulatova, R., Bahl, C. R. H., Andersen, K. B., Theil Kuhn, L., Pryds, N., 2015. Functionally graded ceramics fabricated with side-by-side tape casting for use in magnetic refrigeration. Int. J. Appl. Ceram. Technol 12, 891898.

Caron, L., Ou, Z., Nguyen, T., Thanh, D. C., Tegus, O., Brück., E., 2009. On the determination of the magnetic entropy change in materials with firstorder transitions. J. Magn. Magn. Mater. 321, 35593566.

Engelbrecht, K., Bahl, C., Nielsen, K., 2011. Experimental results for a magnetic refrigerator using three different types of magnetocaloric material regenerators. International Journal of Refrigeration 34, 1132-1140.

Engelbrecht, K., Tusek, J., Nielsen, K., Kitanovski, A., Bahl, C., Poredos, A., 2013. Improved modelling of a parallel plate active magnetic regenerator. J. Phys. D.: Appl. Phys 46, 255002.

Ferreira, L. D. R., Bessa, C. V. X., da Silva, I., Gama, S., 2014. A heat transfer study aiming optimization of magnetic heat exchangers of thermomagnetic motors. Int. J. Refrig. 37, 209-214.

Fujieda, S., Hasegawa, Y., Fujita, A., 2004. Thermal transport properties of magnetic refrigerants $\mathrm{La}\left(\mathrm{Fe}_{x} \mathrm{Si}_{1-x}\right)_{13}$ and their hydrides, and $\mathrm{Gd}_{5} \mathrm{Si}_{2} \mathrm{Ge} 2$ and MnAs. J. Appl. Phys. 95, 24292431. 
Gschneidner Jr., K. A., Pecharsky, V. K., Tsokol, A. O., 2005. Recent developements in magnetocaloric materials. Rep. Prog. Phys. 68, 1479.

Jacobs, S., Auringer, J., Boeder, A., Chell, J., Komorowski, L., Leonard, J., Russek, S., Zimm, C., 2014. The performance of a large-scale rotary magnetic refrigerator. Int. J. Refrigeration 37, 84-91.

Jeppesen, S., Linderoth, S., Pryds, N., Kuhn, L. T., Jensen, J. B., 2008. Indirect measurement of the magnetocaloric effect using a novel differential scanning calorimeter with magnetic field. Review of Scientific Instruments 79 (8), 083901.

Kitanovski, A., Tusek, J., Tomc, U., Plaznik, U., Ozbolt, M., Poredos, A., 2015. Magnetocaloric Energy Conversion: From Theory to Applications. Springer International Publishing, New York.

Lanzarini, J., Barriere, T., Sahli, M., Gelin, J., Dubrez, A., C.Mayer, Pierronnet, M., Vikner, P., 2015. Thermoplastic filled with magnetocaloric powder. Materials and Design 87, 1022-1029.

Lei, T., Nielsen, K., Engelbrecht, K., Bahl, C., Bez, H. N., Veje, C., 2015. Sensitivity study of multi-layer active magnetic regenerators using first order magnetocaloric material $\mathrm{La}(\mathrm{Fe}, \mathrm{Mn}, \mathrm{Si}){ }_{13} \mathrm{H}_{y}$. J. Appl. Phys 118, 014903.

Liu, J., Zhang, M., Shao, Y., Yan, A., 2015. LaFe ${ }_{11.6} \mathrm{Si}_{1.4} / \mathrm{Cu}$ Magnetocaloric Composites Prepared by Hot Pressing. IEEE Trans. Magn. 51, 2501502.

Lyubina, J., Schäfer, R., Martin, N., Schultz, L., Gutfleisch, O., 2010. Novel Design of $\mathrm{La}(\mathrm{Fe}, \mathrm{Si})_{13}$ Alloys Towards High Magnetic Refrigeration Performance. Advanced Materials 22, 3735-3739.

Nielsen, K., Engelbrecht, K., Christensen, D., Jensen, J., Smith, A., Bahl, C., 2012. Degradation of the performance of microchannel heat exchangers due to flow maldistribution. Appl. Therm. Engineer 40, 236.

Pecharsky, V. K., Gschneidner Jr., K. A., 1999a. Magnetocaloric affect and magnetic refrigeration. J. Magn. Magn. Mater. 200, 44.

Pecharsky, V. K., Gschneidner Jr., K. A., 1999b. Magnetocaloric effect from indirect measurements: Magnetization and heat capacity. J. Appl. Phys. $86,565-575$. 
Pryds, N., Clemens, F., Menon, M., Nielsen, P. H., Brodersen, K., Bjørk, R., Bahl, C. R. H., Engelbrecht, K., Nielsen, K. K., Smith, A., 2011. A monolithic perovskite structure for use as a magnetic regenerator. Journal of the American Ceramic Society 94, 2549-2555.

Pulko, B., Tusekek, J., J.D.Moore, Weise, B., Skokov, K., Mityashkin, O., Kitanovski, A., Favero, C., Fajfar, P., Gutfleisch, O., Waske, A., Poredos, A., 2015. Epoxy-bondedlafecosi magnetocaloricplates. J. Magn. Magn 375, $65-73$.

Radulov, I., Skokov, K., nad T. Braun, D. K., Gutfleisch, O., 2015. PolymerBonded $\mathrm{La}(\mathrm{Fe}, \mathrm{Mn}, \mathrm{Si}){ }_{13} \mathrm{H}_{x}$ Plates for Heat Exchangers. IEEE Trans. Magn. 51, 2501204.

Skokov, K. P., Karpenkov, D., Kuzmin, M. D., Radulov, I., Gottschall, T., Kaeswurm, B., Fries, M., Gutfleisch, O., 2014. Heat exchangers made of polymer-bonded La(Fe,Si) $)_{13}$. J. Appl. Phys 115, 17 A941.

Smith, A., Bahl, C., Bjørk, R., Engelbrecht, K., Nielsen, K., Pryds, N., 2012. Materials challenges for high performance magnetocaloric refrigeration devices. Advanced Energy Materials 2, 1288-1318.

Velazquez, D., Castro, M., Palacios, E., Burriel, R., 2014. Practical properties of lafecosi materials to be used in magnetic cooling regerators. Proceedings 6th IIF-IIR International Conference on Magnetic Refrigeration, Victoria, BC, 7-10 September 2014.

Zhang, H., Hu, F., Sun, J., Shen, B., 2013. Effects of interstitial H and/or $\mathrm{C}$ atoms on the magnetic and magnetocaloric properties of $\mathrm{La}(\mathrm{Fe}, \mathrm{Si})_{13^{-}}$ based compounds. Science China Physics, Mechanics and Astronomy 56, 2302-2311. 